\title{
Cernea's classification of the External Branch of the Superior Laryngeal Nerve during Microscopic Thyroidectomy at Gandaki Medical College, Pokhara
}

\author{
Tulika Dubey *1, Brihaspati Sigdel ${ }^{1}$, Rajendra Nepali", Neeraj KC \\ 'Department of ENT, Gandaki Medical College Teaching Hospital and Research Centre
}

\begin{abstract}
Background: Preservation of the external branch of the superior laryngeal nerve (EBSLN) during thyroidectomy is important because its injury may lead to frequent occurrence of vocal fatigue and the inability to perform phonation. The objective of the study was to identify and classify the nerve as per Cernea's classification using operating microscope during thyroidectomy Methods: Between January 2017 to December 2019, we evaluated fifty patients for the position of external branch of superior laryngeal nerve, who underwent microscopic thyroid surgeries in the department of ENThead and neck surgery at Gandaki Medical College. Results: In our study, we dissected a total 59 superior poles of thyroid from 50 patients and identified the nerve in all the cases. Of the total superior poles, $(n=36,61.01 \%)$ had type IIa EBSLN among which 24 was on the right side and 12 on the left followed by ( $\mathrm{n}=19,32.20 \%)$ patients with type IIb EBSLN among which 8 on right and 11 on left side. There were only four poles (6.77\%) of type I with three on the right and one on the left side. Conclusions: The EBSLN can be very efficaciously identified during a microscope assisted thyroidectomy. Cernea type $2 \mathrm{a}$ and $2 \mathrm{~b}$ EBSLNs are in position to be at high risk of injury during ligation of the superior vascular pedicle, which can be avoided by prompt identification through a microscope and a meticulous extra capsular dissection technique.
\end{abstract}

KEYWORDS: Cernea's classification, external branch of superior laryngeal nerve (EBSLN), microscopic thyroidectomy .

\section{*Correspondence:}

Dr Tulika Dubey

Lecturer, ENT Department,

Gandaki Medical College Teaching Hospital and Research Centre, Pokhara, Nepal

Email: dubeytulika7@gmail.com

Submitted: March 22, 2021

Accepted: November 26, 2021

To cite: Dubey T, Sigdel B, Nepali R, Neeraj KC. Cernea's classification of the External Branch of the Superior Laryngeal Nerve during Microscopic Thyroidectomy at Gandaki Medical College, Pokhara. JGMC Nepal.2021;14(2):133-6.

DOI: $10.3126 /$ jgmcn.v14i2.35893

\section{INTRODUCTION}

Studies have shown that subjective voice disturbance after thyroidectomy is very common. Even without injury to the recurrent laryngeal nerves. One possible cause for postoperative dysphonia is injury to the external branch of the superior laryngeal nerve (EBSLN). ${ }^{1,2}$ The EBSLN supplies the cricothyroid muscle. This muscle increases the longitudinal tension of vocal folds and raises the pitch of voice. ${ }^{3}$ The effects of the injury are subtle and include mild to moderate breathy voice and reduction in the average pitch of voice. ${ }^{4}$ The nerve runs in close relation to the upper pole of the thyroid gland and is at risk of injury during dissection. ${ }^{5}$

Cernea et al. reported that an experienced thyroid surgeon had a lower incidence of postoperative cricothyroid muscle dysfunction in cases in which the nerve was searched for and identified than in cases in which no search was performed. Cernea et al. created a three-way system according to the level at which the nerve crosses behind the artery which is shown in table $1 .^{6}$ Their study showed that $37 \%$ of cadaveric nerves were found in a position as to be vulnerable during thyroidectomy. 
Table 1: Cernea's Classification For EBSLN ( Cernea Et Al)

\begin{tabular}{ll}
\hline TYPE I & $\begin{array}{l}\text { The nerve crosses the STA more than } 1 \mathrm{~cm} \text { above } \\
\text { the margin of the superior thyroid pole }\end{array}$ \\
TYPE IIa & $\begin{array}{l}\text { The nerve crosses the STA }<1 \mathrm{~cm} \text { above the margin } \\
\text { of the superior thyroid pole }\end{array}$ \\
TYPE IIb & $\begin{array}{l}\text { The nerve crosses the superior thyroid pedicle below } \\
\text { the margin of the superior thyroid pole }\end{array}$ \\
\hline
\end{tabular}

We tried to evaluate the rate of identification of the EBSLN in 50 thyroidectomies performed over a three year period using microscope assisted thyroidectomy. We feel the Cernea's classification has a clinical implication describing the variants of EBSLN in thyroid surgeries and we hereby report our experience in the identification of EBSLN in a series of consecutive thyroidectomies. This study is intended to explore the potential of operating microscope in determining the type of EBSLN.

\section{METHODS}

Study design and setting: This was a cross sectional study where 50 consecutive patients, aged 11-65 years, who underwent microscopic thyroid surgeries were included in this study. The study was conducted at ENT Department of Gandaki Medical College Research Center.

Duration of study: The study was conducted at Gandaki Medical between January 2017 to December, 2019.

Study population: Study population were the patients who were enrolled for thyroid surgery during the period between January 2017 to December 2019.

Sample size and sampling techniques: Non probability consecutive sampling technique was applied. All the patients fulfilling above inclusion criteria were enrolled in the study.

Surgical technique: We used a microscope assisted approach for each superior pole. The sternohyoid muscle was retracted laterally and the sternothyroid muscle was divided at its midpoint. The gland was retracted inferolaterally while the sternothyroid muscle was bluntly dissected upward. The microscope was used to identify the avascular space between the larynx and the superior thyroid pole and was opened. We used a Zeiss multi-discipline surgical microscope with a $250 \mathrm{~mm}$ ocular lens. During this dissection, the lateral surface of the cricothyroid muscle was exposed and the EBSLN was identified. Its course was traced laterally to the point where it crossed the superior thyroid vessels. We used a rhinoplasty caliper to measure the distance of the nerve from the superior pole. No sharp dissection or electrocautery was used at the superior pole prior to identification of this point. We did not use a nerve stimulator or other laryngeal nerve monitor. We then proceeded to dissect the remainder of the attachments of the thyroid gland.

Data collection technique and data analysis: For each patient, we recorded age, sex, diagnosis, procedure and laterality of the procedure and whether relevant nerves were identified and their Cernea classifications. We analyzed the data using statistical package for social science (SPSS) version 20. Descriptive statistics were computed and presented.

Ethical consideration: The Research Ethics Committee of Gandaki Medical College approved of this study and an informed written consent was taken from each patient prior to the surgery.

\section{RESULTS}

Among the 50 patients enrolled in the study, 86\% were females and $14 \%$ males. The mean of age of the participants was 40.11 years; and 30\% respondents were in the age group of 31 to 40 years and only one respondent was age of above 60 years (Table 2).

Table 2: Sex and Age distribution of the patients $(\mathrm{N}=50)$

\begin{tabular}{lcc}
\hline Variables & Number & Percentage \\
Sex & 43 & 86 \\
Female & 7 & 14 \\
Male & & \\
Age group & 2 & 4 \\
$<20$ & 11 & 22 \\
$21-30$ & 15 & 30 \\
$31-40$ & 7 & 14 \\
$41-50$ & 14 & 28 \\
$51-60$ & 1 & 2 \\
$>60$ & & \\
\hline
\end{tabular}

Numbers of thyroid surgeries done were 22 cases in 2019, 16 in 2018 and 12 in 2017. Among the 50 patients, $(n=33$, $66 \%)$ patients were diagnosed as colloid goitre, $(n=12$, $24 \%)$ as multinodular goitre, $(n=3,6 \%)$ as papillary carcinoma, $(n=1,2 \%)$ as follicular adenoma and $(n=1,2 \%)$ case of follicular carcinoma (Table 3 ).

Table 3: Diagnosis of the Thyroid Pathologies $(\mathrm{N}=50)$

\begin{tabular}{lcc} 
Diagnosis & Number & Percentage \\
Colloid goitre & 33 & 66 \\
Multinodular goitre & 12 & 24 \\
Papillary carcinoma & 3 & 6 \\
Follicular adenoma & 1 & 2 \\
Follicular carcinoma & 1 & 2 \\
\hline
\end{tabular}

With regard to the operative procedures, $(n=26,52 \%)$ 
patients underwent right hemithyroidectomy, $(n=15,30 \%)$ patients had left hemithyroidectomy, $(n=8,16 \%)$ patients underwent total thyroidectomy and $(n=1,2 \%)$ patient had total thyroidectomy with central compartment clearance and lateral neck dissection (Table 4).

Table 4: Operative Procedures for Thyroid Pathologies $(\mathrm{N}=50)$

\begin{tabular}{lcc}
\hline Surgery & Number & $\begin{array}{c}\text { Percentage } \\
\text { (\%) }\end{array}$ \\
Right hemithyroidectomy & 26 & 52 \\
Left hemithyroidectomy & 15 & 30 \\
Total thyroidectomy & 8 & 16 \\
$\begin{array}{l}\text { Total thyroidectomy + central compartment } \\
\text { dissection+ lateral neck dissection }\end{array}$ & 1 & 2 \\
\hline
\end{tabular}

In our study, we dissected a total 59 superior poles of thyroid and identified the nerve in all 50 patients. We classified the location of EBSLN based on Cernea's classification. Of total poles identified, $(n=36,61.02 \%)$ poles had type IIa EBSLN among which 24 was on the right side and 12 on the left followed by $(n=19,32.20)$ poles with type IIb EBSLN among which 8 on right and 11 on left side. There were only $(n=4,6.77)$ poles of type I with 3 on the right and 1 on the left side (Table 5).

Table 5: Laterality and Cernea's classification of EBSLN $(\mathrm{N}=59)$

\begin{tabular}{lcccc}
\hline Type & Right & Left & Total & \\
& Number & Number & Number & Percentage (\%) \\
Type I & 3 & 1 & 4 & 6.77 \\
Type IIa & 24 & 12 & 36 & 61.01 \\
Type IIb & 8 & 11 & 19 & 32.20 \\
Total & 35 & 24 & 59 & 100 \\
\hline
\end{tabular}

No change of voice in the immediate post-operative period and after three weeks of surgery was noted. The fibro-optic flexible nasopharyngolaryngoscopy (FNPL) assessment of true vocal cords after three weeks of surgery showed no abnormality.

\section{DISCUSSION}

The EBSLN provides motor innervation to the cricothyroid muscle that is responsible for elongating and tensing the vocal cord and contributing to the pitch of voice. The injury to the nerve may cause hoarse breathy voice, vocal fatigue or diminished vocal frequency range, especially in regard to raising pitch. Paralysis of EBSLN may not be of much value to many people but can be significant to those whose career fully depends upon the range of voice.

Among all the classifications of the positional variants of
EBSLN, Cernea's classification has by far been the most feasible and practical to give us an idea about which position in relation to the thyroid gland might be risky for the nerve and what can and should be done to prevent any injury to the nerve during thyroid surgeries.

Different identification rates of the EBSLN have been quoted by authors with few not performing routine identifications. ${ }^{7}$ The techniques used for the identification of the EBSLN mentioned in literature include the use of nerve stimulator, the inspection of the distal part of the inferior constrictor muscle and individual ligation of the superior thyroid vessels. ${ }^{6,8-11}$ The lack of uniformity regarding the surgical protocol for identification of the EBSLN is seen because of its variable anatomical course.

The first microsurgical thyroidectomy was reported in 1975 by Atti et al. ${ }^{12}$ So, technically its not a novel technique but rather explored by only a few. Seven et al did a controlled prospective trial for this technique and concluded that microsurgical thyroidectomy is a feasible and efficacious surgical procedure and significantly reduces the complications without increasing the operating time in thyroid surgery procedures. ${ }^{15}$ In our study, we used a simple surgical microscope routinely used for the ENT surgeries, for the identification of the EBSLN and its subsequent classification as per Cernea. We were able to precisely identify the nerve in all the cases. Our prime aim in this study was just the identification of EBSLN for the Cernea's classification.

In our study type IIa and IIb which puts the patient at a greater risk of injury during surgery was identified in $61.01 \%$ and $32.2 \%$ nerves respectively which is pretty much in concordance with the findings of Menon et al where type IIa and IIb was seen in 58\% and $9 \%$ respectively ${ }^{13}$ and Hwang et al where type IIa 56.5\% and type IIb $27.2 \%{ }^{14}$

One could say we that it had been pure luck that we were able to identify the nerve in all the cases, but the magnification provided by the microscope definitely made the job easier and precise. The surgery was time consuming as it took us some time to be oriented to the operating field under the microscope which came across as one of the limitations of the technique but identification of the difficult variants to prevent injury and subsequent complications made it worth the time.

\section{CONCLUSIONS}

Type IIa was the commonest Cernea variant identified in this study and the microscopic aid led to better and exact identification of the nerve thereby preventing iatrogenic 
complications. This technique is not new but definitely needs to be explored more and still has a steep learning curve, this study may encourage fellow surgeons to undertake the method so that we have a experiences to share and most importantly to avoid the "at risk" nerves.

\section{ACKNOWLEDGEMENT}

Without the patients who participated in the study, none of this would have been possible.

\section{CONFLICTS OF INTEREST: None}

\section{SOURCE OF FUNDING: None}

\section{REFERENCES}

1. Lombardi CP, Raffaelli M, D'Alatri L, et al. Voice and swallowing changes after thyroidectomy in patients without inferior laryngeal nerve injuries. Surgery. 2006; 140(6):1026-1032. DOI: 10.1016/j. surg.2006.08.008 PMID: 17188153

2. SinagraDL,Montesinos MR,TacchiVA,etal.Voicechanges after thyroidectomy without recurrent laryngeal nerve injury. J Am Coll Surg. 2004;199(4):556-560. DOI: $\quad 10.1016 /$ j.jamcollsurg.2004.06.020 PMID: 15454138.

3. Perry A. (2008) Speech therapy in ENT practice: scope, science and evidencefor intervention: Gleeson $\mathrm{M}$, ed. Scott-Brown's Otolaryngology, Head and NeckSurgery. (7thedn), Hodder Arnold, Great Britain. DOI: 10.1201/ b15118-187 4. Jansson S, Tisell L Hagne I, Sanner E, StenborgR, Svensson P(1988) Partial SLNlesions before and after thyroid surgery. World J Surg ;12: 522-527. DOI: 10.1007/BF01655439 PMID: 3420935.

5. Bliss RD, Gauger PG, Delbridge, LW (2000) Surgeon's Approach to the Thyroid Gland: Surgical Anatomy and the Importance of Technique. World JSurg; 24: 891-897. DOI: $10.1007 / \mathrm{s} 002680010173$ PMID: 10865032.

6. Cernea CR, Ferraz AR, Furlani J, et al. Identification of the external branch of the superior laryngeal nerve during thyroidectomy. Am J Surg. 1992;164(6):634-9. DOI: $10.1016 / \mathrm{S} 0002-9610(05) 80723-8$
7. Lore JM, Kokocharov SI, Kaufman S, Richmond A, Sundquist N (1998) 38-Year evaluation of a surgical technique to protect the EBSLN during thyroidectomy. Ann Otol Rhinol Laryngol; 107: 1015-1022. DOI: 10.1177/000348949810701204 PMID: 9865631.

8. Jonas J, Bahr R (2000) Neuromonitoring of the EBSLN during thyroid surgery. Am J Surg ;179: 234-236. DOI: 10.1016/S0002-9610(00)00308-1

9. Lennquist S, Cahlin C, Smeds S. The superior laryngeal nerve in thyroid surgery Surgery. 1987 Dec;102(6):999-1008.

10. Lekacos NL, Miligos ND, Tzaedis PJ, Majiatis S, Patoulis J (1987) The SLN inthyroidectomy. Am Surg; 53: 610612.

11. Choksy SA, Nicholson ML (1996) Prevention of voice changes in singers by using a nerve stimulator to identify the external laryngeal nerve. Br J Surg; 83:1131-1132. DOI: 10.1002/bjs.1800830831 PMID: 8869325.

12. Attie, J.N.Khafif, R.A. Preservation of parathyroid glands during total thyroidectomy. Improved technic utilizing microsurgery. Am. J. Surg. 1975;130: 399-404. DOI: $10.1016 / 0002-9610(75) 90472-9$

13. Menon RR, Murali S, Nair CG, Babu MJC, Jacob P. Correlation between the Cernea lassification of External Branch of Superior Laryngeal Nerve in Relation to the Ultrasound-based Volume of Thyroid Gland. Indian JEndocrinol Metab. 2017;21(6):845-847. DOI: 10.4103/ijem.IJEM_230_17 PMID: 29285446.

14. Hwang $H$,Lee $H$, Kim $w$, Woo $s$, Lee j, Bae j, Kim h. The anatomy of the external branch ofthe superior laryngeal nerve in Koreans. Asian journal of surgery. Jan 2013;36(1):13-19 DOI: 10.1016/j.asjsur.2012.08.003 PMID: 23270820.

15. Seven H ,Calis A.B, Vural C, Turgut S. Microscopic thyroidectomy: A prospective controlled trial. Eur. Arch. Otorhinolaryngol. 2005;262: 41-44. DOI: 10.1007/s00405-004-0740-1 PMID: 15744511. 